DOI: 10.15393/j9.art.2013.374

Владимир Алексеевич Воропаев

доктор филологических наук, профессор кафедры истории русской титературы, Московский государственный университет имени М. В. Ломоносова (Москва, Российская Федерация) voropaevvl@bk.ru

\title{
ОКНО В МИР ЕВАНГЕЯЬСКИХ ИСТИН: СТИХИЯ РУССКОЙ НАРОДНОЙ РЕЧИ В ПОЭМЕ Н. В. ГОГОЯЯ «МЕРТВЫЕ ДУШИ»
}

Аннотация: В статье исследуется стихия русской народной речи и ее евангельский подтекст в поэтике Н. В. Гоголя. В эстетике писателя народные пословицы и притчи - важнейший источник самобытности, из которого должны черпать вдохновение русские поэты. Утверждается, что в поэме «Мертвые души» «пословичный» способ обобщения стал одним из важнейших принципов художественной типизации. Чем более обобщенный вид принимают образные картины и характеристики персонажей, в которых автор выражает сущность того или иного явления, ситуации или человеческого типа, тем более они приближаются к традиционным народно-поэтическим формулам.

Выявлен скрытый смысл пословицы «Русский человек задним умом крепок». С этим свойством национального ума, который сродни уму народных пословиц, Гоголь связывает высокое предназначение России. Завершая первый том, автор обращается к иносказательной форме притчи, которая приобретает ключевое значение для восприятия поэмы. Вырастая в символ обобщающего значения, ее персонажи концентрируют в себе важнейшие, родовые черты и свойства героев «Мертвых душ». Гротескно-выразительные образы Кифы Мокиевича и Мокия Кифовича помогают оглядеть героев поэмы со всех сторон, а не с одной только стороны, где они мелочны и ничтожны. Герои Гоголя вовсе не обладают заведомо отвратительными, уродливыми качествами, которые необходимо полностью искоренить для того, чтобы исправить человека. Богатырские свойства и практичность Собакевича, хозяйственная бережливость Плюшкина, созерцательность и радушие Манилова, молодецкая удаль и энергия Ноздрева - качества сами по себе вовсе не плохие и отнюдь не заслуживают осуждения. Но все это, как любил выражаться Гоголь, льется через край, доведено до излишества, проявляется в извращенной, гипертрофированной форме

Ключевые слова: Евангелие, поэтика, Гоголь, пословицы и поговорки, притча, народная речь

«У Гоголя не было предшественников в русской литера(и не могло быть) образцов в иностранных литературах. О роде его поэзии, до появления ее, не было и намеков» 
$[1,123]$. Впоследствии историками литературы было накоплено немало наблюдений о связи Гоголя с различными литературно-художественными явлениями - от Гомера и Библии до Вальтера Скотта и малороссийской повести начала XIX в. И все же вывод Белинского, думается, в значительной мере верен и сейчас. Еще первый биограф Гоголя П. А. Кулиш указывал на важнейший источник необычайной оригинальности его творений - народную стихию, их питающую $[4,84]$. В этом, как представляется, и заключается разгадка своеобразия творческой манеры Гоголя и, в частности, особенностей поэтики его главного творения - поэмы «Мертвые души».

С самого начала Гоголь мыслил свое сочинение в общерусском, общенациональном масштабе. 7 октября 1835 г. он сообщал А. С. Пушкину:

Начал писать Мертвых душ. <...> Мне хочется в этом романе показать хотя с одного боку всю Русь (XI, 33)1.

Много позднее, в письме к В. А. Жуковскому 1848 г., Гоголь пояснял замысел своего творения:

Уже давно занимала меня мысль большого сочиненья, в котором бы предстало все, что ни есть и хорошего и дурного в русском человеке, и обнаружилось бы пред нами видней свойство нашей русской природы (XV, 11).

Воплощение такого грандиозного замысла требовало и соответствующих художественных средств. В эстетике Гоголя народные пословицы и притчи - важнейший источник самобытности, из которого должны черпать вдохновение русские поэты. Невозможно понять «Мертвые души» без учета фольклорной традиции и в первую очередь пословичной стихии, пронизывающей всю ткань поэмы. В «Авторской исповеди» Гоголь писал:

Чем более я обдумывал мое сочинение, тем более видел, что не случайно следует мне взять характеры, какие попадутся, но избрать одни те, на которых заметней и глубже отпечатлелись истинно русские, коренные свойства наши (VI, 224).

И поскольку в русских пословицах и поговорках наиболее полно выразились важнейшие особенности национального 
характера, человеческие качества, одобряемые народом или отвергаемые им, в «Мертвых душах» «пословичный» способ обобщения стал одним из важнейших принципов художественной типизации. Чем более обобщенный вид принимают образные картины и характеристики персонажей, в которых Гоголь выражает сущность того или иного явления, ситуации или человеческого типа, тем более они приближаются к традиционным народнопоэтическим формулам.

Характер Манилова - помещика «без задора», пустопорожнего мечтателя - «объясняется» через пословицу:

Один Бог разве мог сказать, какой был характер Манилова. Есть род людей, известных под именем: люди так себе, ни то ни се, ни в городе Богдан, ни в селе Селифан, по словам пословицы (V, 24).

Медвежья натура Собакевича, имевшего «крепкий и на диво стаченный образ», в хозяйстве которого все было «упористо, без пошатки, в каком-то крепком и неуклюжем порядке», находит свое итоговое определение в пословичной формуле:

Эк наградил-то тебя Бог! вот уж точно, как говорят, неладно скроен, да крепко сшит!.. (V, 103).

Характеры эпизодических персонажей поэмы порою полностью исчерпываются пословицами или пословичными выражениями.

Максим Телятников, сапожник: что шилом кольнет, то и сапоги, что сапоги, то и спасибо, и хотя бы в рот хмельного $(\mathrm{V}, 100)$.

Заседатель Дробяжкин был «блудлив, как кошка...» (V, 188) (ср.: «Блудлив, как кошка, а труслив, как заяц»²). Мижуев был один из тех людей, которые, кажется, никогда не согласятся «плясать по чужой дудке», а кончится всегда тем, что пойдут

...поплясывать как нельзя лучше под чужую дудку, - словом, начнут гладью, а кончат гадью (V, 68).

Гоголь любил выражать заветные свои мысли в пословицах. Идея «Ревизора» сформулирована им в эпиграфе-пословице: «На зеркало неча пенять, коли рожа крива». Эта народная пословица напоминает о Евангелии, о чем современники Гоголя, принадлежавшие к Православной Церкви, 
прекрасно знали [см.: 2]. В сохранившихся главах второго тома «Мертвых душ» важное значение для понимания авторского замысла имеет пословица: «Полюби нас черненькими, а беленькими нас всякий полюбит».

Известно, - говорил Гоголь, - что если сумеешь замкнуть речь ловко прибранной пословицей, то сим объяснишь ее вдруг народу, как бы сама по себе ни была она свыше его понятия (V, 179).

Вводя пословицы в художественную ситуацию «Мертвых душ», Гоголь творчески использует заключенный в них смысл. В десятой главе почтмейстер, сделав предположение, что Чичиков есть «не кто другой, как капитан Копейкин», публично сознался, что совершенно справедлива поговорка: «Русский человек задним умом крепок». «Коренной русской добродетелью» - задним, «спохватным» (ср.: «Русский ум задний ум. Русский ум - спохватный ум»3), покаянным умом в избытке наделены и другие персонажи поэмы, но прежде всего сам Павел Иванович Чичиков.

К этой пословице у Гоголя было свое, особое отношение. Обычно она употребляется в значении «спохватился, да поздно», и крепость задним умом расценивается как порок или недостаток. В Толковом словаре Владимира Даля находим: «Русак задом (задним умом) крепок»; «Умен, да задом»; «Задним умом догадлив». В его же «Пословицах Русского народа» читаем: «Всяк умен: кто сперва, кто опосля»; «Задним умом дела не поправишь»; «Кабы мне тот разум наперед, что приходит опосля». Но Гоголю было известно и другое толкование этой поговорки. Так, известный собиратель русского фольклора первой половины XIX в. И. М. Снегирев усматривал в ней выражение свойственного русскому народу склада ума: «Что Русский и после ошибки может спохватиться и образумиться, о том говорит его же пословица: Русский задним умом крепок» [4; II, 27]; «Так в собственно Русских пословицах выражается свойственный народу склад ума, способ суждения, особенность воззрения <...> Коренную их основу составляет многовековой, наследственный опыт, этот задний yм, которым крепок Русский...» $[5,22]$.

Заметим, что глубинный смысл этой народной мудрости ощущался не только в эпоху Гоголя. Наш современник писатель Леонид Леонов замечал: 
Нет, не о тугодумии говорится в пословице насчет крепости нашей задним умом, - лишний раз она указывает, сколь трудно учесть целиком все противоречия и коварные обстоятельства, возникающие на просторе неохватных глазом территорий ${ }^{4}$.

В размышлениях Гоголя о судьбах родного народа, его настоящем и историческом будущем «задний ум или ум окончательных выводов, которым преимущественно наделен перед другими русский человек», является тем коренным «свойством русской природы», которое и отличает русских от других народов. С этим свойством национального ума, который сродни уму народных пословиц, «умевших сделать такие великие выводы из бедного, ничтожного своего времени $<. . .>$ и которые говорят только о том, какие огромные выводы может сделать нынешний русский человек из нынешнего широкого времени, в которое нанесены итоги всех веков» (VI, 195), Гоголь связывает высокое предназначение России.

Для поэтики «Мертвых душ» особенно характерен язык художественных ассоциаций, скрытых аналогий и уподоблений, к которому постоянно прибегает автор. В анекдотических ситуациях, «вставных» эпизодах, пословицах и поговорках Гоголь рассыпает «подсказки» читателю. Но всего этого ему как будто кажется недостаточным. Наконец, содержание первого тома он обобщает в маленькой лаконичной притче, сводя все многообразие героев поэмы к двум персонажам.

...Жили в одном отдаленном уголке России два обитателя. Один был отец семейства, по имени Кифа Мокиевич, человек нрава кроткого, проводивший жизнь халатным образом. Семейством своим он не занимался; существованье его было обращено более в умозрительную сторону и занято следующим, как он называл, философическим вопросом: «Вот, например, зверь, - говорил он, ходя по комнате, - зверь родится нагишом. Почему же именно нагишом? Почему не так, как птица, почему не вылупливается из яйца? Как, право, того: совсем не поймешь натуры, как побольше в нее углубишься!» Так мыслил обитатель Кифа Мокиевич $(\mathrm{V}, 236)$.

Не случайно Кифа Мокиевич занят философическим вопросом о рождении зверя из яйца. Этот гоголевский образ 
очень хорошо «укладывается» в известное пословичное выражение о «выеденном яйце» и создан, в сущности, как развертывание этого выражения, как реализация заключенной в нем метафоры. В то время как «теоретический философ» Кифа Мокиевич занимается разрешением вопроса, не стоящего и выеденного яйца, его сын, богатырь Мокий Кифович, проявляет себя соответствующим образом на поприще практической деятельности.

Был он то, что называют на Руси богатырь, - говорится в притче о Мокии Кифовиче, - и в то время, когда отец занимался рожденьем зверя, двадцатилетняя плечистая натура его так и порывалась развернуться. Ни за что не умел он взяться слегка: все или рука у кого-нибудь затрещит, или волдырь вскочит на чьем-нибудь носу. В доме и в соседстве все, от дворовой девки до дворовой собаки, бежало прочь, его завидя; даже собственную кровать в спальне изломал он в куски. Таков был Мокий Кифович... (V, 236).

Образ Мокия Кифовича также восходит к фольклорной традиции. В одном из черновых вариантов притчи, где этот персонаж назван еще Иваном Мокиевичем, Гоголь прямо указывает на народнопоэтический первоисточник образа: «обращик Мокиев<ича> - Лазаревич» ${ }^{5}$ (имеется в виду «Повесть о Еруслане Лазаревиче»). В основу образа Мокия Кифовича положены черты этого сказочного героя, ставшего символом русского богатыря.

И как будет Уруслан десяти лет, выдет на улицу: и ково возмет за руку, из того руку вырвет, а ково возмет за ногу, тому ногу выломат 6 .

Традиционный эпический образ, широко известный по народным источникам, Гоголь наполняет нужным ему «современным» смыслом. Наделенный необыкновенным даром - невиданной физической силой - Мокий Кифович растрачивает его попусту, причиняя одно беспокойство и окружающим, и самому себе. Понятно, что речь в притче идет не об отрицании свойств и особенностей ее персонажей, а скорее об их недолжном проявлении. Плохо не то, что Кифа Мокиевич мыслитель, а Мокий Кифович - богатырь, а то, 
как именно они используют данные им от природы свойства и качества своей натуры.

Здесь ли, в тебе ли не родиться беспредельной мысли, когда ты сама без конца? - восклицает автор в патетическом размышлении о Руси. - Здесь ли не быть богатырю, когда есть место, где развернуться и пройтись ему $(\mathrm{V}, 213)$.

Завершая первый том поэмы, Гоголь недаром обращается к иносказательной форме притчи. «Красна речь с притчею» - гласит русская пословица. В контексте всего первого тома гоголевская притча приобретает особое, ключевое значение для восприятия поэмы. Вырастая в символ обобщающего значения, ее персонажи концентрируют в себе важнейшие, родовые черты и свойства героев «Мертвых душ».

Философски-умозрительно - в духе Кифы Мокиевича существование Манилова:

Дома он говорил очень мало и большею частью размышлял и думал <...> Хозяйством нельзя сказать, чтобы он занимался, он даже никогда не ездил на поля, хозяйство шло как-то само собою $(\mathrm{V}, 25)$.

О чем размышляет Манилов, в бесплодных мечтаниях издерживающий жизнь свою? О подземном ходе, мосте через пруд с лавками для крестьян, о том, как было бы хорошо

...под тенью какого-нибудь вяза пофилософствовать о чемнибудь, углубиться!.. (V, 38).

Неуклюжий Собакевич, подобно Мокию Кифовичу, не умеющему ни за что взяться слегка, уже «с первого раза» наступил Чичикову на ногу, сказавши: «Прошу прощения». О сапоге этого «на диво сформированного помещика» сказано, что он был

...такого исполинского размера, которому вряд ли где можно найти отвечающую ногу, особливо в нынешнее время, когда и на Руси начинают выводиться богатыри $(\mathrm{V}, 18)$.

Образ Собакевича, унаследовавшего от своих древних предков недюжинную физическую силу и поистине богатырское здоровье («пятый десяток живу, ни разу не был болен»), создан с пародийным использованием традиционных 
элементов сказочной поэтики. Этот современный российский богатырь, совершающий свои подвиги за обеденным столом, съедает сразу целую «половину бараньего бока», ватрушки у него «каждая была гораздо больше тарелки», «индюк ростом в теленка».

У меня когда свинина - всю свинью давай на стол, баранина всего барана тащи, гусь - всего гуся! (V, 96).

Сам человек здоровый и крепкий, практичный помещик, Собакевич, «казалось, хлопотал много о прочности». Но практичность этого рачительного хозяина оборачивается самым настоящим расточительством.

На конюшни, сараи и кухни были употреблены полновесные и толстые бревна, определенные на вековое стояние. <...> Даже колодец был обделан в такой крепкий дуб, какой идет только на мельницы да на корабли (V, 91).

Гротескно-выразительные образы Кифы Мокиевича и Мокия Кифовича помогают оглядеть героев поэмы со всех сторон, а не с одной только стороны, где они мелочны и ничтожны.

Все можно извратить и всему можно дать дурной смысл, человек же на это способен, - говорил Гоголь. - Но надобно смотреть на вещь в ее основании и на то, чем она должна быть, а не судить о ней по карикатуре, которую из нее сделали. <...> Много есть таких предметов, которые страждут из-за того, что извратили смысл их; а так как вообще на свете есть много охотников действовать сгоряча, по пословице: «Рассердясь на вши, да шубу в печь», то через это уничтожается много того, что послужило бы всем на пользу (VI, 57, 63).

Герои Гоголя вовсе не обладают заведомо отвратительными, уродливыми качествами, которые необходимо полностью искоренить для того, чтобы исправить человека. Богатырские свойства и практичность Собакевича, хозяйственная бережливость Плюшкина, созерцательность и радушие Манилова, молодецкая удаль и энергия Ноздрева - качества сами по себе вовсе не плохие и отнюдь не заслуживают осуждения. Но все это, как любил выражаться Гоголь, льется через край, доведено до излишества, проявляется в извращенной, гипертрофированной форме. 
Обратимся теперь к Чичикову. В нем соединение всех «задоров» гоголевских героев. Ему автор заглядывает глубоко в душу, подчас передоверяет свои задушевные мысли. Еще в детстве Павлуша обнаружил «большой ум со стороны практической». Выказывая «прямо русскую изобретательность» и удивительную «бойкость в деловых делах», Павел Иванович всю жизнь занимался делом. В наиболее концентрированной, афористической форме эта черта главного героя поэмы выражена в его «пословичном» монологе:

...зацепил - поволок, сорвалось - не спрашивай. Плачем горю не пособить, нужно дело делать (V, 226).

«Делом» именуется в поэме и афера Чичикова с мертвыми душами. Весь свой незаурядный практический ум, волю в преодолении препятствий, знание людей, упорство в достижении цели этот неутомимый и хитроумный русский Одиссей растрачивает в деле... не стоящем выеденного яйца. Именно так говорит о своем «деле» Чичиков, выведенный из себя непонятливостью Коробочки:

Есть из чего сердиться! Дело яйца выеденного не стоит, а я стану из-за него сердиться $(\mathrm{V}, 54)$.

Как видим, автор заставляет своих героев «проговариваться» о себе в пословицах. Пословицы же в «Мертвых душах» функционально значимы, несут в себе гораздо больший смысл, чем это может показаться на первый взгляд.

Приобретение «херсонского помещика» расценивается чиновниками как «благое дело». По словам самого Чичикова, он

...стал наконец твердой стопою на прочное основание» и «более благого дела не мог бы предпринять (V, 142).

На чем же пытается основать свое благополучие Павел Иванович? На мертвых душах! На том, чего нет, что ничего не стоит, чего быть не может! На пустоте. Тщета предприятий и замыслов Чичикова в том, что все они лишены духовного основания. Путь Чичикова бесплоден. Бесплодность эта и выражается через мудрость народного речения о деле, не стоящем выеденного яйца. Эта поговорка впервые появляется задолго до финала первого тома, и ею же Гоголь подводит итог делу Чичикова. И этот традиционный народный 
вывод, венчающий похождения героя, содержит в себе и приговор ему, и возможность, по мысли автора, его грядущего возрождения. Недаром во втором томе Муразов повторяет про себя:

Презагадочный для меня человек Павел Иванович Чичиков. Ведь если бы с этакой волей и настойчивостью да на доброе дело! (V, 349).

Художественному мышлению Гоголя свойственны архитектурные ассоциации (подобные ассоциации восходят к Евангелию, точнее, к притчам Христа, и были широко распространены в литературе и искусстве христианского мира). Хорошо известно его сравнение «Мертвых душ» с «дворцом, который задуман строиться в колоссальных размерах» (из письма к В. А. Жуковскому от 26 июня (н. ст.) 1842 г.) (XII, 55). Тогда понятным становится и упоминание о двух обитателях отдаленного уголка России, которые «нежданно, как из окошка, выглянули в конце нашей поэмы» (V, 237). Продолжая метафору писателя, можно сказать, что притча - это окошко, позволяющее заглянуть в глубину художественного мира его книги.

Сходный образ встречается в статье Гоголя «Шлецер, Миллер и Гердер» (1834):

Может быть, некоторым покажется странным, что я говорю о Шлецере как о великом зодчем всеобщей истории, тогда как его мысли и труды по этой части улеглись в небольшой книжке, изданной им для студентов, - но эта маленькая книжка принадлежит к числу тех, читая которые, кажется, читаешь целые томы; ее можно сравнить с небольшим окошком, к которому приставивши глаз поближе, можно увидеть весь мир. Он вдруг осеняет светом и показывает, как нужно понять, и тогда сам собою наконец видишь все (VII, 320).

\section{Примечания}

Здесь и далее цитируется по: Гоголь Н. В. Полн. собр. соч. и писем: В 17 т. / Сост., подготовка текстов и коммент. И. А. Виноградова, В. А. Воропаева. М.-Киев, 2009-2010. Номер тома и страницы указывается в круглых скобках после цитаты. 
2 Собрание 4291 древних Российских пословиц. Печатано при Имп. Московском университете. 1770 г. 244 с.

3 Князев В. Русь. Сборник избранных пословиц, присловок, поговорок и прибауток. Л.: Б. изд., 1924. 115 с. Здесь с. 83.

4 Цит. по: Леонов Л. М. Собр. соч.: В 10 т. Т. 10. М.: Художественная литература, 1984. С. 544-545.

5 Цит. по: Гоголь Н. В. Полн. собр. соч. и писем: В 23 т. Т. 7. Кн. 1 / Тексты и коммент. подготовили: Н. Л. Виноградская, П. Ю. Гуревич, Е. Е. Дмитриева, И. А. Зайцева, Ю. В. Манн, О. К. Супронюк, А. С. Шолохова. М.: Наука, 2012. С. 747.

6 Хрестоматия по древнерусской литературе / Сост. Н. К. Гудзий. Изд. 8-е. М.: Просвещение, 1973. С. 371.

\section{Список литературы}

1. Белинский В. Г. Собрание сочинений: В 9 т. М.: Худ. лит-ра, 1982. Т. 8. $783 \mathrm{c}$.

2. Воропаев В. А. «На зеркало неча пенять...» (Смысл эпиграфа и «немой сцены» в комедии Н. В. Гоголя «Ревизор») // Русская речь. М., 2002. № 6. С. 9-15.

3. <Кулиш П. А.> Опыт биографии Н. В. Гоголя, со включением до сорока его писем. СПб.: В типографии Эдуарда Праца, 1854. 208 с.

4. Снегирев И. Русские в своих пословицах. Рассуждения и исследования об отечественных пословицах и поговорках. Кн. 1-4. М.: В Университетской типографии, 1831-1834.

5. Снегирев И. М. Русские народные пословицы и притчи / Изд. подготовил Е. А. Костюхин. М.: Индрик, 1999. 624 с. 
Vladimir Alekseevich Voropaev

\author{
Ph.D. in Philology, \\ Professor of the Department of History of Russian Literature, \\ Lomonosov Moscow State University \\ (Moscow, Russian Federation) \\ voropaevvl@bk.ru
}

\title{
THE WINDOW TO THE WORLD \\ OF THE GOSPEL TRUTH: THE POWER OF RUSSIAN FOLK SPEECH IN NIKOLAI GOGOL'S NOVEL DEAD SOULS
}

\begin{abstract}
The article studies the function of Russian folk speech and its evangelical implication in Nikolai Gogol's poetics. Folk proverbs and parables is the key source of national identity in Gogol's aesthetics, which should inspire all Russian poets. The paper asserts that the proverbial method of generalization is one of the most significant principles of typification in Gogol's novel Dead Souls. The author expresses the essence of this or that phenomenon, a situation or a human type using imaginative pictures and traits of characters. The more generalized form they take, the more they resemble the traditional folk and poetic formulas.

The article also reveals the hidden message of a Russian proverb Russians are good at thinking in hindsight ("Russkiy chelovek zadnim umom krepok"). This characteristic of the Russian mind is the one with which Gogol connects the great destiny of Russia. At the end of his first volume the author resorts to the allegorical form of a parable that plays a key role in the perception of the novel. Transforming into the generalized symbols, its characters accumulate the most significant generic features and qualities of Dead Souls' characters. The grotesque images of Kifa Mokiyevich and Mokiy Kifovich help to look at the characters of the novel from every possible side, not from one side only that shows them as small-minded and worthles people. Gogol's characters do not possess definitely disgusting and ugly qualities which should be eliminated for the sake of people's improvement. Sobakevich's powerful physique and pragmatism, Plushkin's thrift, Manilov's meditativeness and cordiality, as well as Nozdryov's valor and energy are not bad qualities at all and do not deserve condemnation. However, all of them as Gogol used to say are carried to extremes and take the perverse and exaggerated forms.
\end{abstract}

Keywords: Gospel, poetics, Gogol, proverbs and sayings, parable, folk speech

\section{References}

1. Belinskiy V. G. Sobranie sochineniy: v 9 tomakh [Complete Works: in 9 Vols.]. Moscow, Khudozhestvennaya literatura Publ., 1982, vol. 8. 783 p.

2. Voropaev V. A. "Na zerkalo necha penyat'...» (Smysl epigrafa $i$ "nemoy stseny» v komedii N. V. Gogolya «Revizor») ["You Must Not Blame the Mirror for Showing a Crooked Face ..." (Meaning of the Epigraph and the 
Final "Silent Scene" in Nikolai Gogol's Comedy "The Revizor")]. Moscow, Russkaya rech Publ., 2002, no. 6, pp. 9-15.

3. <Kulish P. A.> Opyt biografii N. V. Gogolya, so vklyucheniem do soroka ego pisem [An Attempt of Nikolai Gogol's Biography Study (with up to 40 Gogol's Letters Included)]. St. Petersburg, Eduard Prats Publ., 1854. 208 p.

4. Snegiryov I. Russkie v svoikh poslovitsakh. Rassuzhdeniya i issledovaniya ob otechestvennykh poslovitsakh i pogovorkakh [Russians in Their Proverbs. Reasoning and Researches of Local Proverbs and Sayings]. Moscow, 18311834, books 1-4.

5. Snegiryov I. M. Russkie narodnye poslovitsy i pritchi [Russian Folk Proverbs and Parables]. Moscow, Indrik Publ., 1999. 624 p. 